\title{
Design and Research of a New Type of Ultrasonic Vibration De-Gluing Device
}

\author{
Zihao Liu*, Zhen Yin*, Jie Ying, Peng Zhang \\ College of Mechanical Engineering, Suzhou University of Science and Technology, Suzhou, China \\ Email: ^liuzihao2000@foxmail.com, ‘yinzhen12@mail.usts.edu.cn
}

How to cite this paper: Liu, Z.H., Yin, Z., Ying, J. and Zhang, P. (2021) Design and Research of a New Type of Ultrasonic Vibration De-Gluing Device. World Journal of Engineering and Technology, 9, 891-903. https://doi.org/10.4236/wjet.2021.94061

Received: October 23, 2021

Accepted: November 26, 2021

Published: November 29, 2021

Copyright $\odot 2021$ by author(s) and Scientific Research Publishing Inc. This work is licensed under the Creative Commons Attribution International License (CC BY 4.0).

http://creativecommons.org/licenses/by/4.0/

(c) (i) Open Access

\begin{abstract}
In this paper, a new type of ultrasonic vibration de-gluing device has been designed to remove the cured epoxy resin adhesive that overflowed from the aluminum alloy structural parts in the high-speed train carriages. At present, manual removal is used to remove the cured epoxy resin adhesive that overflows at the bonding site. This method has low removal efficiency and leads to poor surface quality of the parts. The new type of ultrasonic vibration de-gluing device can solve these problems. Modal analysis and harmonic response analysis are carried out on the ultrasonic vibration oscillator system in the ultrasonic vibration de-gluing device, and the reasonable structure parameters and resonance frequency of the ultrasonic vibration oscillator system are determined. Finally, the impedance test and de-gluing effect test are carried out on the prototype of the ultrasonic vibration de-gluing device to verify the feasibility and practicability of the new type of ultrasonic vibration de-gluing device. The results show that the ultrasonic vibration de-gluing device's stable resonant operating frequency is $28,270 \mathrm{~Hz}$, and the average error between the simulation and experimental results of the resonant operating frequency is less than $3 \%$, which validates the simulation model.
\end{abstract}

\section{Keywords}

Ultrasonic Vibration, Epoxy Resin Adhesive, Finite Element Analysis, Ultrasonic De-Gluing

\section{Introduction}

Some of the aluminum alloy structures in the high-speed train carriages need to be bonded with epoxy resin adhesive. However, the excess epoxy resin adhesive will overflow and solidify at the bonding edge, which greatly affects the appearance of the structures and leads to the inaccurate assembly of the aluminum al- 
loy structures. At present, manual removal is used to remove the cured epoxy resin adhesive that overflowed from the bonding. This method not only consumes a lot of labor, but also has low removal efficiency [1]. In addition, the surface quality of the aluminum alloy structures removed manually is poor.

Laser cleaning technology is an industrial technology to remove epoxy resin adhesive [2]. This technology utilizes the interaction between laser and material. It has the characteristics of high machining precision and no contact with the processed object, so that epoxy resin adhesive can be selectively removed. At present, laser cleaning technology is mostly used for the removal of epoxy coatings on aerospace equipment, and the equipment cost is relatively high. However, the thickness of epoxy resin adhesive removal is usually below $0.1 \mathrm{~mm}$, which is much lower than the thickness of cured epoxy resin adhesive overflowing from aluminum alloy structural parts in high-speed train carriages. In addition, epoxy resin laser cleaning will generate harmful gas, which is not friendly to the environment.

A set of ultrasonic vibration de-gluing devices was developed to remove the cured epoxy resin adhesive that overflowed from the aluminum alloy structural parts after bonding. In order to design and optimize the structure of the ultrasonic vibration oscillator system, finite element analysis was carried out on the ultrasonic vibration oscillator system in the ultrasonic vibration de-gluing device. The impedance test and de-gluing test were carried out on the prototype of the ultrasonic vibration de-gluing device. The feasibility and practicability of the new type of ultrasonic vibration de-gluing device are verified. Compared with the traditional manual removal and laser cleaning technology, the ultrasonic vibration de-gluing device can achieve a balance of processing speed and precision, thus improving the removal efficiency and quality.

\section{Overall Structure and Working Principle of the Ultrasonic Vibration De-Gluing Device}

Figure 1 shows the structure sketch of the new type of ultrasonic vibration de-gluing device. The device mainly consists of ultrasonic transducer, amplitude transformer, the cutter head, device housing and handle. The ultrasonic transducer, amplitude transformer and the cutter head are assembled into the ultrasonic vibration oscillator system. The ultrasonic vibration transducer is connected to the rear of the amplitude transformer through a stud, the cutter head is connected to the front of the amplitude transformer through a stud, and the amplitude transformer is connected to the device housing through a flange. The amplitude transformer is a stepped structure with an arc transition [3]; the cutter head is also designed as a stepped structure. The connecting section between the cutter head and the amplitude transformer is a cylindrical section, and the front of the cutter head is a flat edge structure. This structure can also amplify the amplitude, which is conducive to amplifying the amplitude at the end of the cutter head. The handle is connected to the device shell. The ultrasonic power supply is connected to the electrodes of the ultrasonic transducer through wires. 


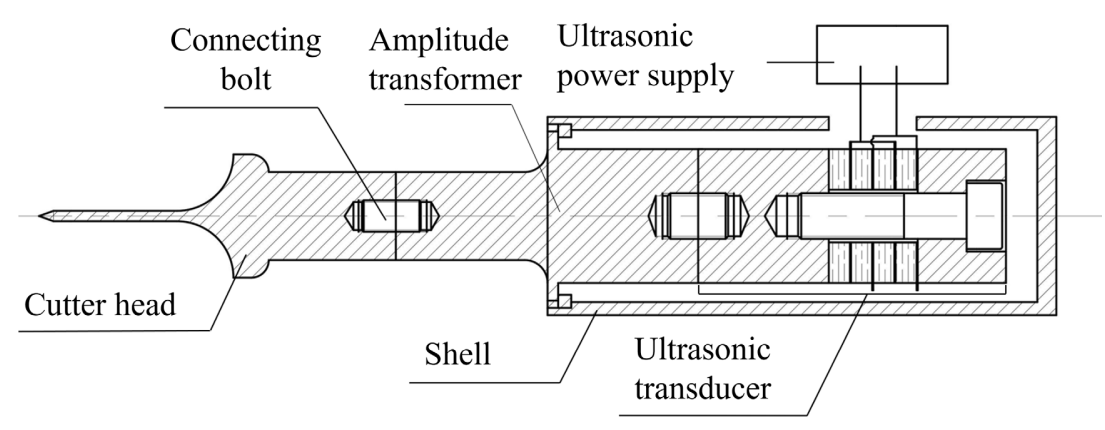

Figure 1. Structure sketch of the ultrasonic vibration de-gluing device.

When the transducer receives the alternating signal from the ultrasonic power supply, it will generate axial high-frequency vibration. The amplitude transformer amplifies the vibration amplitude and transmits it to the cutter head, driving it to vibrate at high frequency [4]. When the cutter head comes into contact with the overflowing epoxy resin adhesive, the cured epoxy resin adhesive will be broken into powder by high-frequency vibration, which can be easily removed.

In order to verify the feasibility of such structure theoretically, a finite element analysis of the device model is required.

\section{Finite Element Analysis of the Ultrasonic Vibration Oscillator System in the Ultrasonic Vibration De-Gluing Device}

\subsection{Model Analysis of the Ultrasonic Vibration Oscillator System}

After the preliminary design of ultrasonic vibration de-gluing device is completed, the modal analysis of the ultrasonic vibration oscillator system in the ultrasonic vibration de-gluing device is carried out using ANSYS Workbench. The natural frequency and vibration model of the ultrasonic vibration oscillator system can be determined through modal analysis.

The materials of the parts in the ultrasonic vibration oscillator system materials are defined separately. The anisotropic elastic parameter matrix of PZT-8 is added to the material library, and its density is defined as $7500 \mathrm{~kg} / \mathrm{m}^{3}$. The fastening studs in the ultrasonic transducer are defined as 45 steel, the four piezoelectric ceramic plates are defined as PZT-8, the four electrode plates are defined as brass, the rear cover plate of the ultrasonic transducer and the amplitude transformer are defined as 304 stainless steel, the front cover plate of the ultrasonic transducer is defined as hard aluminum 2021, the connecting bolts between the amplitude transformer and the cutter head are defined as 45 steel, and the cutter head is defined as titanium alloy TC4 [5]. The mesh element size is set to $1.5 \mathrm{~mm}$, the frequency solution range is $0-30,000 \mathrm{hz}$, the solution result is set as total deformation, and the limitation of modal solutions is set up to 100. Finally, 50 modes are found, and 3 longitudinal vibration modes are extracted. The natural frequency of the oscillator system is shown in Table 1.

The third-class modal shape diagram of the ultrasonic vibration oscillator system is shown in Figure 2. It illustrates that the node with the largest amplitude is 
Table 1. Three-class modal frequency table.

\begin{tabular}{cc}
\hline Class & Frequency \\
\hline 1 & 402.1 \\
2 & 12,212 \\
3 & 28,491 \\
\hline
\end{tabular}

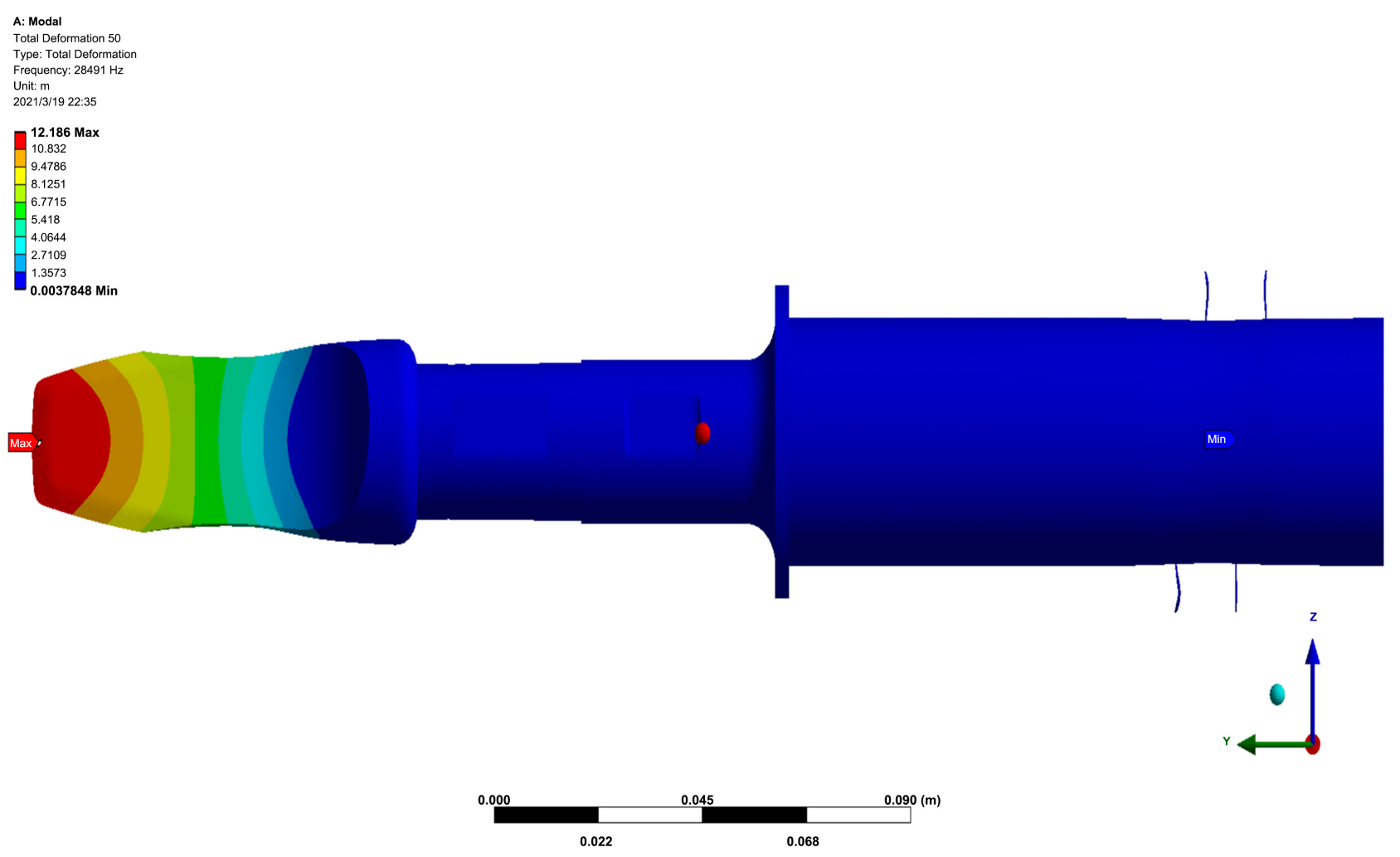

Figure 2. Vibration mode of the ultrasonic vibration oscillator system.

located at the front edge of the cutter head. This modality's frequency is 28,491 $\mathrm{Hz}$, which is close to the ideal operating frequency of $28,000 \mathrm{~Hz}$, with an error of $1.75 \%$. Besides, the frequency obtained by analysis is basically consistent with the theoretical design frequency. Through the post 1 processing program in ANSYS APDL, the node displacement vector diagram of the ultrasonic vibration oscillator system is obtained, as shown in Figure 3. This graph can visually display the displacement direction and displacement size of each node in the ultrasonic vibration oscillator system. The frequency of the modality and the node displacement vector diagram can provide a certain reference value for the structural optimization of the device.

Figure 4 shows the amplitude curve of the ultrasonic vibration oscillator system along the axis. The left end is the output side of the ultrasonic vibrator system, which mainly vibrates axially along the $\mathrm{Y}$ direction, and the amplitudes in the $\mathrm{X}$ and $\mathrm{Z}$ directions are both less than $0.4 \%$ of the amplitudes in the $\mathrm{Y}$ direction. It indicates that the ultrasonic vibrator oscillator system mainly vibrates 


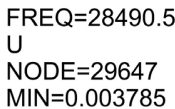

$\mathrm{MIN}=0.003785$

$M A X=12.1857$

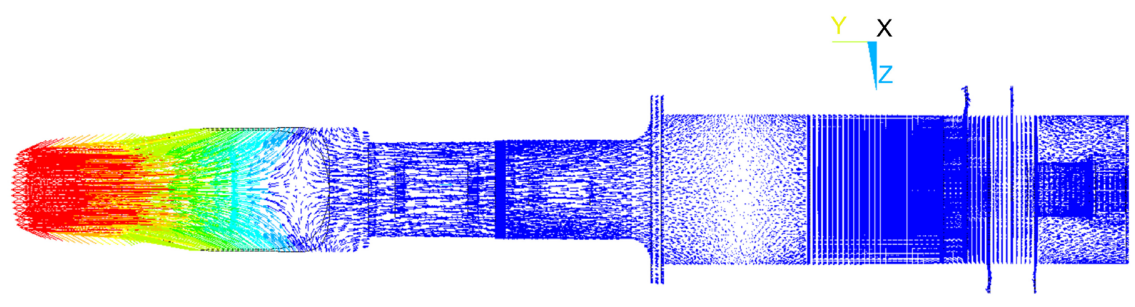

$0.0037851 .35733^{2.71088} 4.06442^{5.41797} 6.77151^{8.12506} 9.47866^{10.8321} 12.1857$

Figure 3. Vector displacement diagram of the ultrasonic vibration oscillator system.

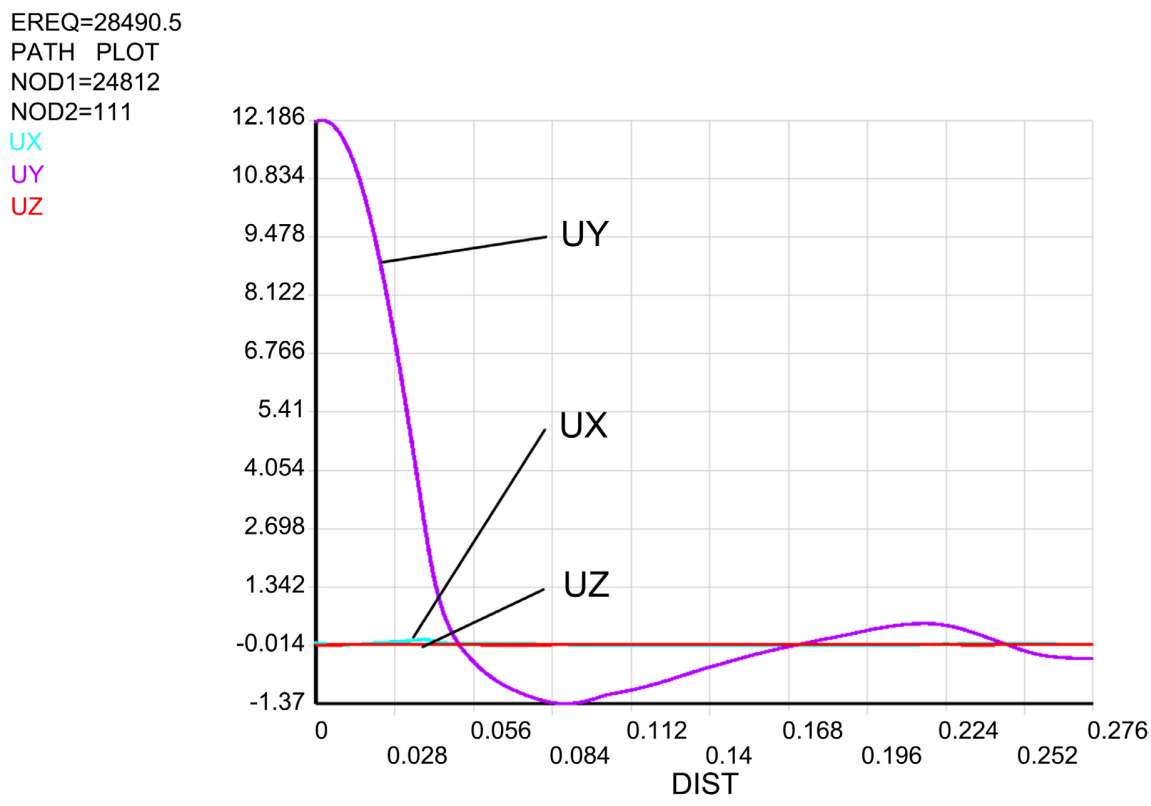

Figure 4. Amplitude curve of the ultrasonic vibration oscillator system along the axis.

axially in the $\mathrm{Y}$ direction in this modality. In addition, the oscillator system can obtain a large amplitude ratio, which can reach 24 . It shows that the structure can effectively amplify the amplitude from the ultrasonic transducer.

\subsection{Harmonic Response Analysis of the Ultrasonic Vibration Oscillator System}

To determine the steady-state response of the ultrasonic vibration oscillator system electrified by voltage signal, it is necessary to perform harmonic response analysis based on the modal analysis of the ultrasonic vibration oscillator system. 
There are multiple methods for the harmonic response analysis of the ultrasonic vibration oscillator system. In the current work, a simple and adaptable approach that combines the commands and the MEMS ACT plug-in is used. The analysis type is set as harmonic response analysis, and the calculate method is set as full method. By installing MEMS ACT plug-in, the four PZT-8 piezoelectric ceramics in the ultrasonic transducer are defined as piezoelectric bodies to simulate the vibration state of the ultrasonic transducer after obtaining sinusoidal AC power. The polarization directions of the piezoelectric ceramics are set by changing the polarization of different direction reference system. The four positive polar surfaces of piezoelectric ceramics are defined as the name selection "Volt", and the three negative polar surfaces are defined as name selection "Ground". To accurately simulate the sinusoidal voltage that energizes the transducer, the $1400 \mathrm{~V}$ sinusoidal alternating current with a frequency of 28,000 $\mathrm{Hz}$ and a current of $0.08 \mathrm{~A}$ is energized to the name selection "Volt" by inserting APDL commands. The number of search sub steps is set to 100. After solving, the vibration displacement of the ultrasonic vibration oscillator system at 28,700 $\mathrm{hz}$ is extracted from all the results, as shown in Figure 5. The vibration displacement frequency of the ultrasonic vibration oscillator system is close to the vibration modal frequency, and the amplitude in $\mathrm{Y}$ direction at the tool tip of the oscillator system is $22.18 \mu \mathrm{m}$, which is consistent with the expected result of the designed ultrasonic vibration de-gluing device.

The frequency response post processor in the Workbench is used to obtain the variation curve of the amplitude of the node at the output end of the ultrasonic vibration oscillator system with the frequency, as shown in Figure 6. When the frequency reaches $28,700 \mathrm{hz}$, the amplitude of the node reaches the peak value,

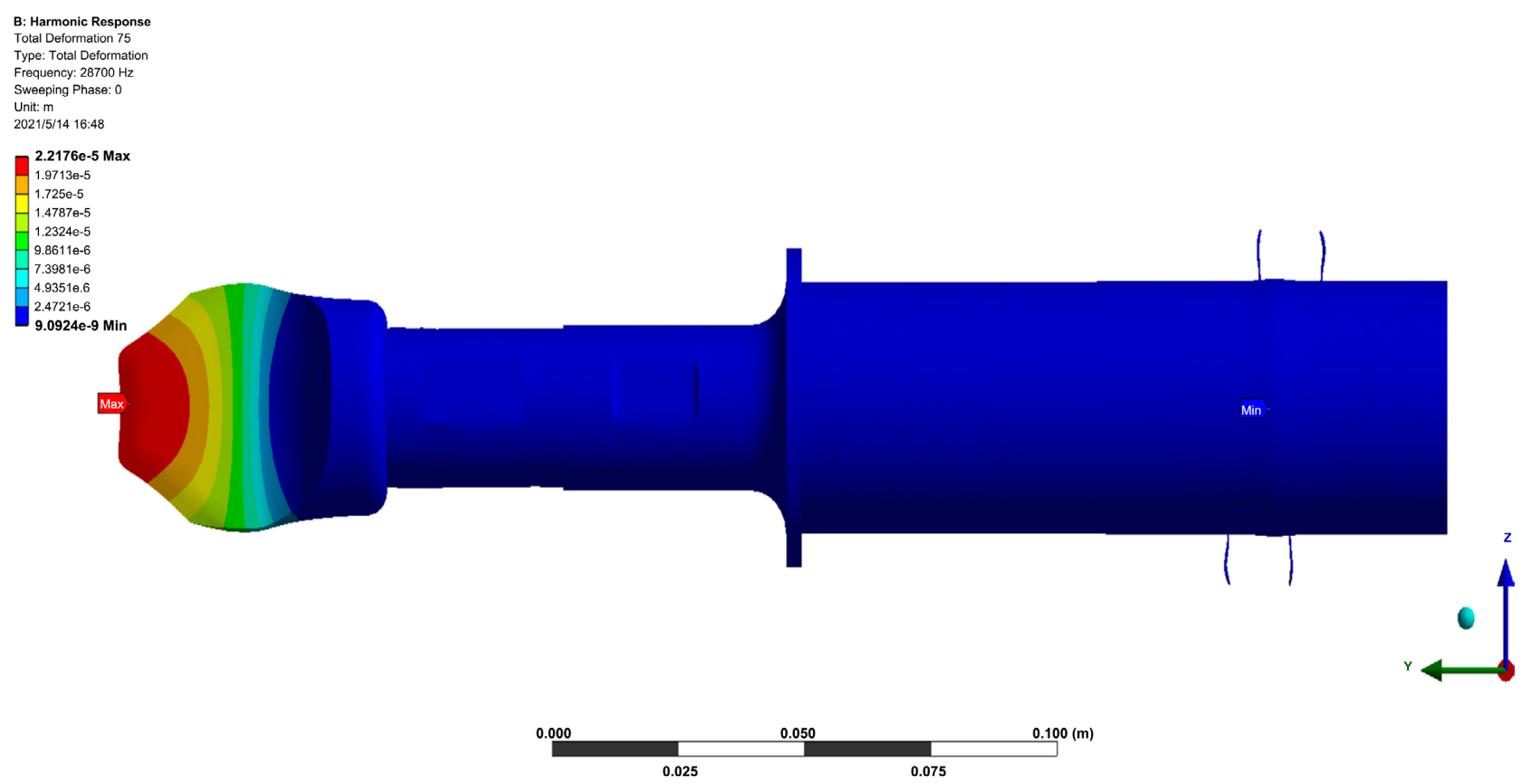

Figure 5. Harmonic response deformation of the ultrasonic vibration oscillator system. 


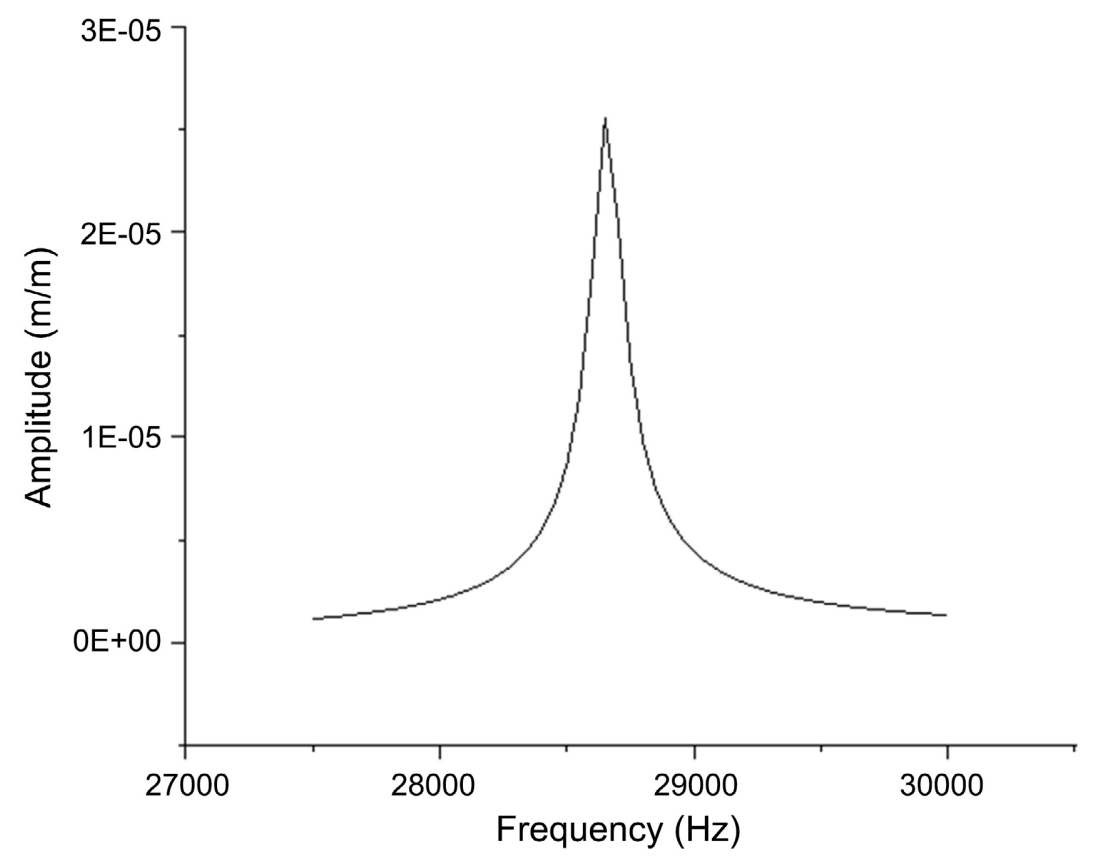

Figure 6. Amplitude curve at output of the ultrasonic vibration oscillator system.

which is $22.18 \mu \mathrm{m}$. This amplitude can meet the needs of theoretical design and practical use. By using the piezo attachment plot post processor in workbench for analysis, the $\mathrm{Y}$ admittance curve of the ultrasonic vibration oscillator system is obtained, as shown in Figure 7. Through the post-processing function of piezo impedance plot, the positive impedance diagram of the oscillator system is obtained, as shown in Figure 8. The impedance and admittance data obtained by the finite element analysis of workbench have certain reference value for the impedance matching for the oscillator system and ultrasonic power supply [6].

\section{Experimental Study on Machining of Ultrasonic Vibration Glue Removal Device}

\subsection{Impedance Test Experiment of Ultrasonic Vibration Glue Removal Device}

Since the finite element analysis has fully validated the theoretical feasibility of the ultrasonic vibration oscillator system in the ultrasonic vibration de-gluing device, the prototype of the ultrasonic vibration de-gluing device was manufactured for experiments, which can verify its practical feasibility.

The impedance test experiment is used to measure the impedance parameters of the ultrasonic vibration de-gluing device in the ultrasonic vibration de-gluing device, to provide a basis for the impedance matching between the ultrasonic vibration de-gluing device and the ultrasonic power supply. The admittance circle (Figure 9) and impedance curve (Figure 10) of the ultrasonic vibration de-gluing device are measured by the "pv90a" impedance analyzer. The measured impedance data of the ultrasonic vibration de-gluing device is very close to the finite element analysis results, and the error is less than $4.5 \%$. It is verified that the 


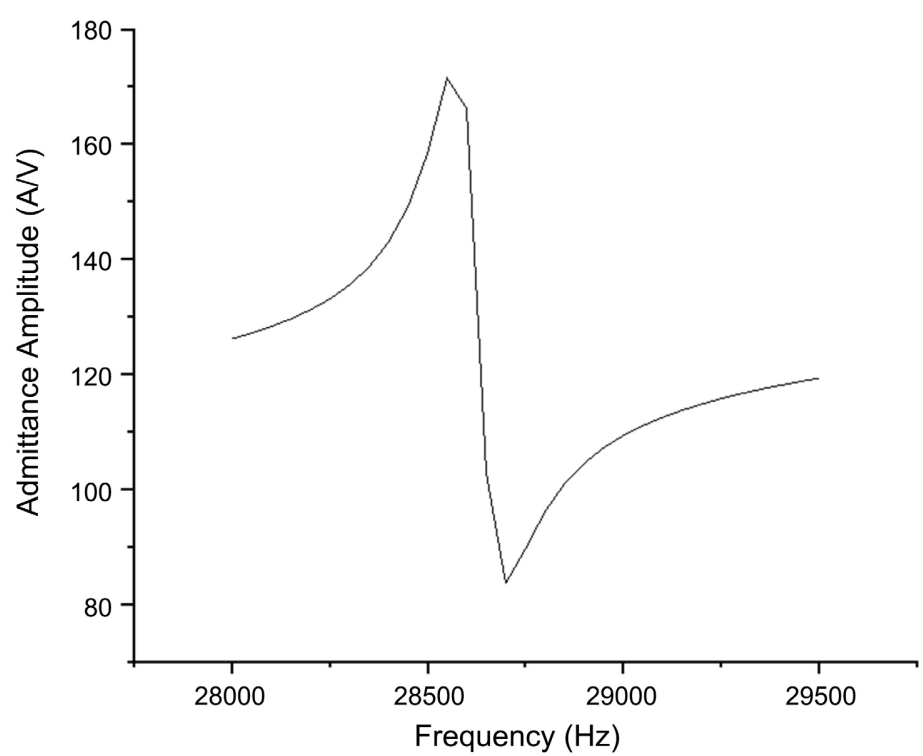

Figure 7. Y-admittance curve of the ultrasonic vibration oscillator system.

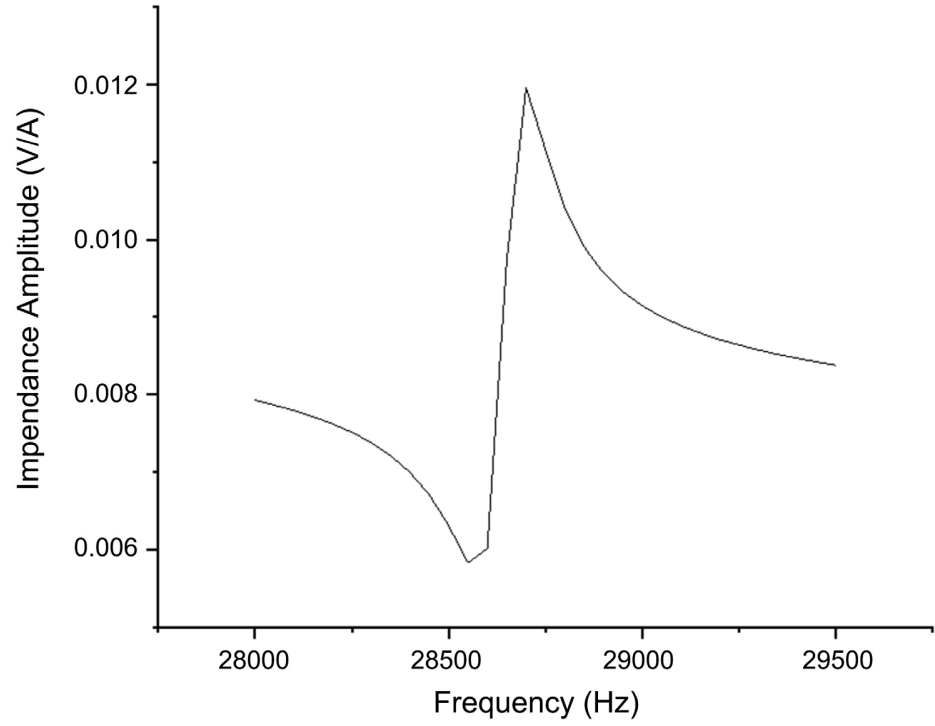

Figure 8. Impedance simulation curve of the ultrasonic vibration oscillator system.

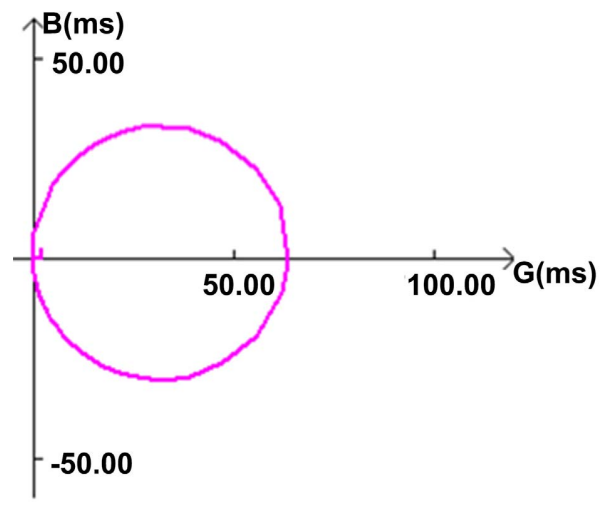

Figure 9. Admittance circle. 


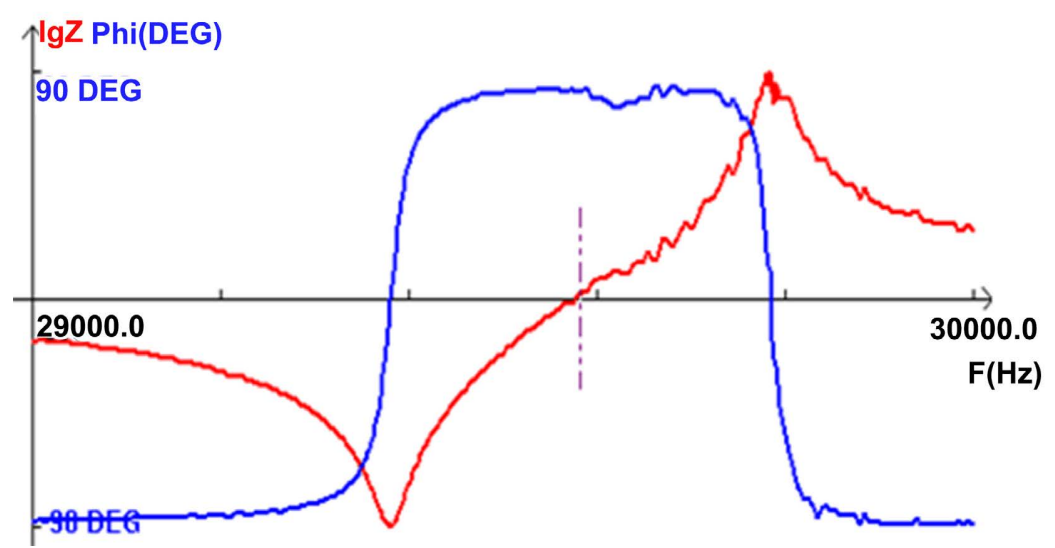

Figure 10. Impedance curve of the ultrasonic vibration de-gluing device.

finite element analysis results can guide the design of the ultrasonic vibration de-gluing device and circuit impedance matching [7].

\subsection{Test of the Ultrasonic Vibration De-Gluing Device}

Figure 11 shows the processing schematic diagram of the ultrasonic vibration de-gluing device. The blue irregular solid is the epoxy resin adhesive remained to be processed. The ultrasonic vibration de-gluing device vibrates along the axis of the device and forms an angle of $25^{\circ}$ with the horizontal plane. The thickness of the cured epoxy resin adhesive overflowed from aluminum alloy structural parts is within $3 \mathrm{~mm}$, which is mainly removed horizontally during de-gluing. Therefore, the vertical force required for de-gluing is less than the horizontal force. The results measured with an electronic dynamometer show that when the epoxy resin adhesive is removed at an angle of $25^{\circ}$, the kinetic energy of the axial vibration of the unit can be utilized to the maximum. The epoxy resin adhesive can be removed at a speed of $1.2 \mathrm{~m}^{2} / \mathrm{h}$ with a thrust of only $28 \mathrm{~N}$ at such an angle. The epoxy resin adhesive in Figure 11 is removed along the side of the aluminum alloy, and the red part is the processed surface.

As shown in Figure 12, an epoxy resin adhesive de-gluing platform has been built, and an ultrasonic power supply with a rated frequency of $28,000 \mathrm{~Hz}$ is used to power the ultrasonic vibration de-gluing device. The rated power of the power supply is $800 \mathrm{~W}$, the default output frequency is $28,000 \mathrm{~Hz}$, and the frequency can be tracked within the range of $\pm 5000 \mathrm{~Hz}$.

The ultrasonic power supply generates a sinusoidal voltage power with a peak voltage of $1400 \mathrm{~V}$ to the ultrasonic vibration de-gluing device, so that the ultrasonic vibration de-gluing device can continuously and stably perform the de-gluing operation. The working current of the ultrasonic vibration de-gluing device is $0.08 \mathrm{~A}$, and its stable resonant working frequency is $28,270 \mathrm{~Hz}$, which is close to the finite element analysis results. The error of natural frequency of the finite element analysis is within $3 \%$, which can verify that the finite element analysis results have a guiding role in the design, manufacture, and application of the ultrasonic vibration de-gluing device. 


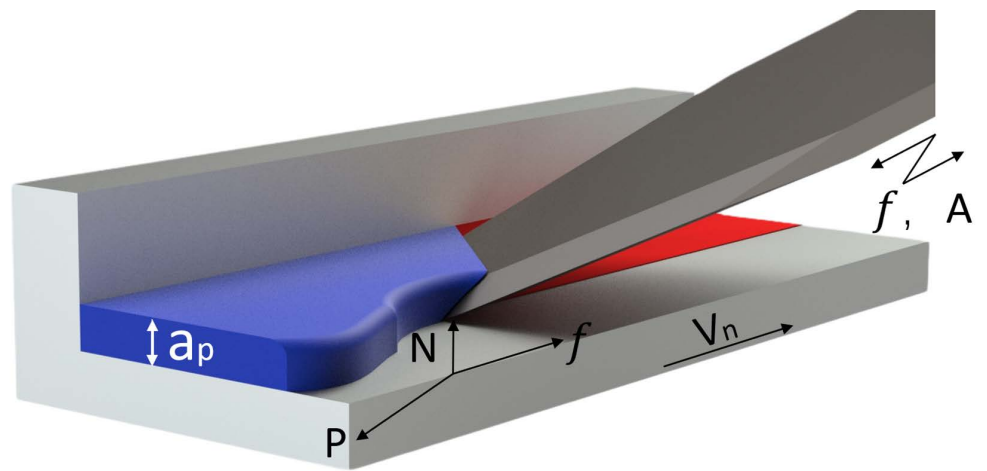

Figure 11. Machining diagrammatic sketch of the ultrasonic vibration de-gluing device.

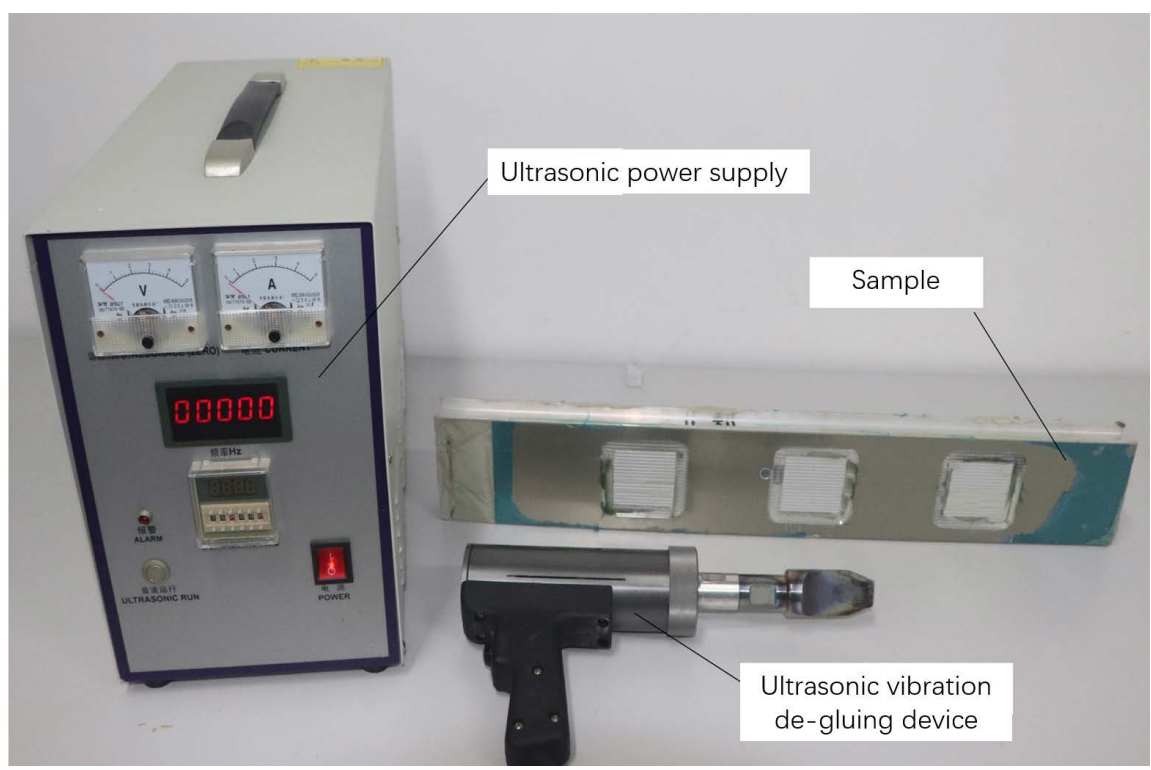

Figure 12. Platform for the de-gluing test of the ultrasonic vibration de-gluing device.

The experimental sample is a $700 \mathrm{~mm} \times 120 \mathrm{~mm} \times 32 \mathrm{~mm}$ hollow aluminum alloy structural part, the overflow area of the cured epoxy resin adhesive to be processed is $25 \mathrm{~mm} \times 80 \mathrm{~mm}$, and the thickness of the epoxy resin adhesive is $2.5 \mathrm{~mm}$. The ultrasonic vibration de-gluing device is used to remove the cured epoxy resin adhesive in this area. After $30 \mathrm{~s}$ of de-gluing operation, the appearance comparison of the samples before and after de-gluing is shown in Figure 13. The $2.5 \mathrm{~mm}$ thick cured epoxy resin adhesive is removed, and the processing surface is relatively smooth. For the manual removal method, it is almost impossible to remove the overflow cured epoxy resin adhesive when using $50 \mathrm{~N}$ thrust. When using $200 \mathrm{~N}$ thrust, it can only remove the cured epoxy resin adhesive with low efficiency. For the cured epoxy resin adhesive with a thickness of $2.5 \mathrm{~mm}$, it can only remove at a speed of $0.01 \mathrm{~m}^{2} / \mathrm{h}$, and the removal surface quality is poor. The ultrasonic vibration de-gluing device with a thrust of only $28 \mathrm{~N}$ can quickly remove the cured epoxy resin adhesive. For the cured epoxy resin adhesive with a thickness of $2.5 \mathrm{~mm}$, it can remove the epoxy resin adhesive at the speed of $1.2 \mathrm{~m}^{2} / \mathrm{h}$. The ultrasonic vibration de-gluing device can break the 


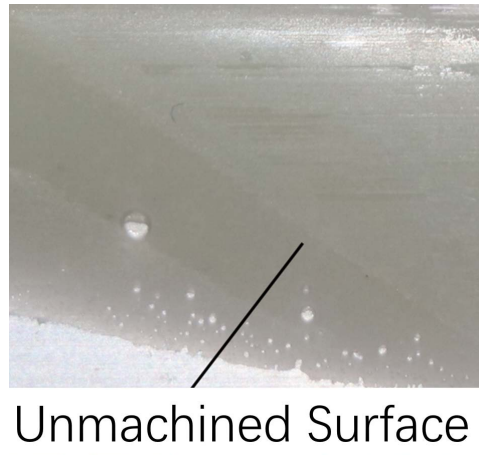

(a)

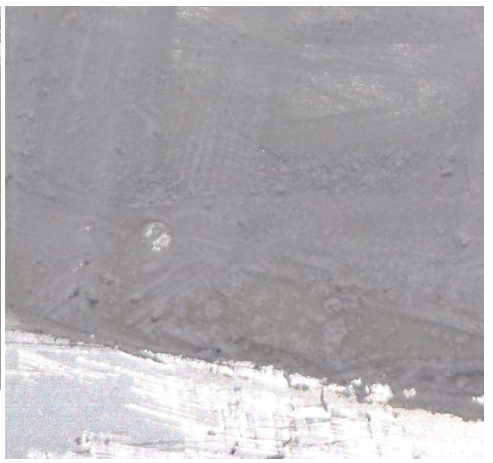

(b)

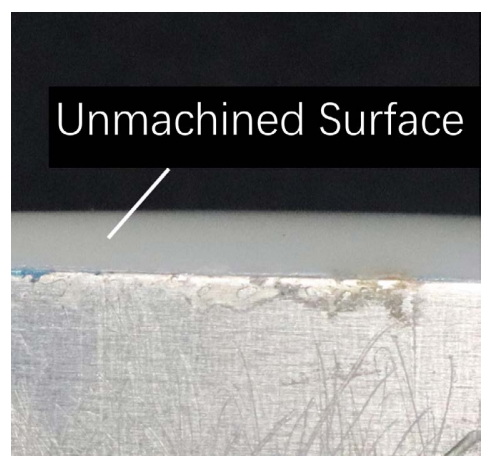

(c)

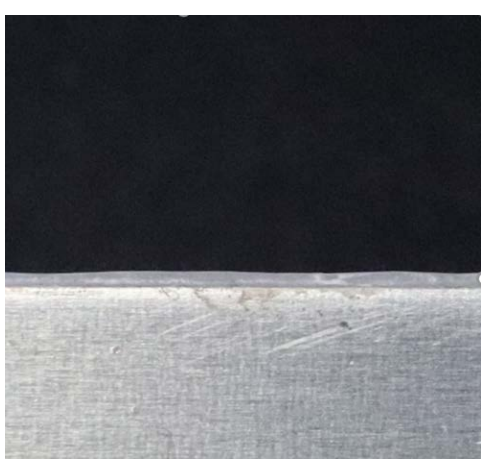

(d)

Figure 13. Comparison of the sample before and after de-gluing. (a) Top view before de-gluing; (b) Top view after de-gluing; (c) Main view before de-gluing; (d) Main view after de-gluing.

overflowing cured epoxy resin adhesive into powder through high-frequency vibration. With the dust collection system, it can ensure the health of operators, improve the removal efficiency of the epoxy resin adhesive and reduce environmental pollution [8].

\section{Conclusions}

In this article, a new type of ultrasonic vibration de-gluing device with a resonant frequency of $28,270 \mathrm{hz}$ was developed to solve the problem of removing the overflowed and cured epoxy resin adhesive on the aluminum alloy structural parts in the high-speed train carriages.

Herein, the structure of the new ultrasonic vibration de-gluing device was designed and optimized through finite element analysis. The vibration mode, amplitude-frequency curve, admittance, impedance, and other data of the new ultrasonic vibration de-gluing device have been obtained through experiments, which can provide references for the design and manufacture of the new ultrasonic vibration de-gluing device. At the same time, it provided a theoretical basis for the impedance matching for the ultrasonic power supply and ultrasonic vibration de-gluing device. Through the impedance analysis and the working frequency test of the ultrasonic vibration de-gluing device, the guiding function of the finite element analysis method on the design of the ultrasonic vibration 
de-gluing device is verified.

The new type of ultrasonic vibration de-gluing device is used to remove 2.5 $\mathrm{mm}$ thick cured epoxy resin, and the de-gluing speed can reach $1.2 \mathrm{~m}^{2} / \mathrm{h}$. It can be seen that the use of the ultrasonic vibration de-gluing device can not only greatly improve the de-gluing efficiency, but also improve the surface quality of de-gluing, which verifies the feasibility and practicability of the new ultrasonic vibration de-gluing device.

The ultrasonic vibration de-gluing device can remarkably increase the processing efficiency of the aluminum alloy structural parts in high-speed train carriages. In addition, it can save lots of labor and make the aluminum alloy structural parts beautiful and practical. In addition, it can also be applied to other vehicles other than high-speed trains, such as e de-gluing work of aluminum alloy structural parts in buses and light rail cars.

\section{Conflicts of Interest}

The authors declare no conflicts of interest regarding the publication of this paper.

\section{References}

[1] Gupta, S.K. and Shukla, D.K. (2020) Effect of Stress Rate on Shear Strength of Aluminium Alloy Single Lap Joints Bonded with Epoxy/Nanoalumina Adhesives. In ternational Journal of Adhesion and Adhesives, 99, Article ID: 102587. https://www.sciencedirect.com/science/article/pii/S0143749620300488?via\%3Dihub https://doi.org/10.1016/j.ijadhadh.2020.102587

[2] Zhou, L.J. (2017) Research on Laser Cleaning Application Technology of Resin Matrix Composite Surface Coating. Master Thesis, Nanchang Aviation University, Nanchang, China.

https://kns.cnki.net/KCMS/detail/detail.aspx?dbname=CMFD201801\&filename $=10$ 18800374.nh

[3] Wang, S. and Meng, C. (2012) Design of the Amplitude Transformer in Ultrasonic Vibration System. Advanced Materials Research, 538-541, 2776-2780.

[4] Li, B., Li, Y. and Meng, X. (2013) Study on Parameter Optimization Design of U1trasonic Horn. Mechanical Design and Manufacturing, 60-63. https://www.cnki.net/kcms/doi/10.19356/j.cnki.1001-3997.2013.11.018.html https://doi.org/10.4028/www.scientific.net/AMR.538-541.2776

[5] Liu, D. (2016) Study on the Cutting Temperature of Serrated Chip While Machining Titanium Alloy TC4. 2016 International Conference on Applied Mechanics, Mechanical and Materials Engineering (AMMME 2016), Xiamen, China, 18-19 December 2016, 299-303.

[6] Yin, Z., Li, H., Li, Y., Xie, O. and Zhang, Z.W. (2010) Study on Characteristics of a New Ultrasonic Internal Grinding System Based on Finite Element. Manufacturing Technology and Machine Tools, 27-31.

[7] Yin, Z., Li, H., Li, Y. and Xie, O. (2010) Simulation and Experimental Research on a New Vibrator of Ultrasonic Internal Grinding System. Mechanical Design and Manufacturing, 187-189.

https://www.cnki.net/kcms/doi/10.19356/j.cnki.1001-3997.2010.08.079.html https://doi.org/10.4028/www.scientific.net/KEM.455.402 
[8] Zhang, X.J. (2018) Study on Comprehensive Treatment System of Waste Gas and Dust under Complex Environmental Conditions. Railway Energy Conservation, Environmental Protection, Safety and Health, 8, 304-308+330.

https://www.cnki.net/kcms/doi/10.16374/j.cnki.issn2095-1671.2018.0074.html 